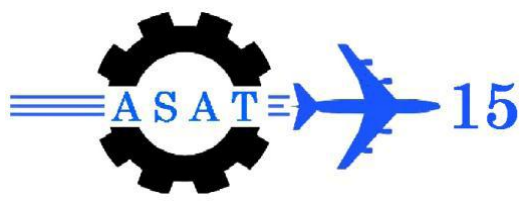

\title{
Evaluation of Surface Displacement Equation due to Tunneling in Cohesionless Soil
}

\begin{abstract}
S. A. Mazek*
Abstract: Construction of tunnels in soft ground induces soil movement, which could seriously affect the stability of existing structures. Evaluation of the effect of tunnel construction on the soil movement requires the solution of a complex soil-structure interaction problem.

Finite element method (FEM) is considered as a good numerical tool to model tunnel system performance. The soil stresses and the soil displacements around a tunnel system are affected by the tunnel construction. The influence zone depends on subsoil properties, tunnel depth, tunnel size, and tunnel support system.

In the present study, finite elements analysis (FEA) is used to model soil-tunnel system performance based on a case study to investigate surface displacement due to tunneling. The Greater Cairo metro tunnel (Line 3) is considered in the present study as case study. The surface displacements obtained by surface displacement equation (SDE) proposed by Peck (1969) and Schmidt (1969) are presented and discussed. The main objective of this study is to examine surface displacements obtained by the FEA with those obtained by the SDE based on different sand soil types. However, the SDE does not consider the impact of different sand soil types on the surface settlement due to tunneling.

The study focuses on the parameters used in the SDE based on different sand soil densities. The limitation of the parameters used in the SDE is discussed and established to predict the surface displacement due to tunneling at different sand soil densities.
\end{abstract}

Keywords: Tunnels, surface settlement, surface displacement equation, deformations.

\section{Introduction}

Tunnels solve many problems such as waste water, power supplies, and traffic jam (Mazek and El-Tehawy, 2008). Several tunnels have been constructed worldwide to solve the transportation problems such as the Greater Cairo Metro and El-Azhar road tunnels (ElNahhas, 1999; NAT, 1993, 1999, 2010). These tunnels are considered as major projects in Cairo city. There are technologies to assist in excavation such as tunneling boring machine (TBM) and cut and cover method (Bicel and Kuesel, 1982).

It is necessary to investigate the geotechnical problems related to tunneling for better understanding the performance of the tunnel system. Many geotechnical problems were encountered during the construction of the Greater Cairo metro, El-Azhar road tunnels, and the Greater Cairo sewage tunnel. Most problems are related to the damage of surrounding buildings due to surface and subsurface ground subsidence (Abu-Krisha, 2001). Tunneling in

Egyptian Armed Forces, Egypt; samazek@yahoo.com 
cohesionless soil is a sophisticated process leading to move surface and subsurface structures (Mroueh and Shahrour, 2008; Mazek and El-Tehawy, 2008). Ground movement results from tunneling work through soft ground due to the associated stress change due to tunnel advancing.

Darabi et al. (2012) presented an appropriate model to predict the behavior of the tunnel in Tehran No. 3 subway line. They employed empirical methods to determine the variation of radial displacements along the longitudinal direction of a tunnel. They also determined the tunnel deformation using numerical analyses. Elsayed (2011) used 2-D Finite Element Analysis (FEA) to model two phases of tunneling process through rocks. First phase, the excavation phase was responsible to determine the pre-lining rock mass deformations and the reduced in-situ stresses. Second phase, the interaction phase modeled the compatibility of the rock-lining system. The deformations and stresses of the rock-lining system and the final rock mass pressure acting on the lining were determined. Cavalaro et al. (2011) analyzed the influence of the contact deficiencies between the segmented tunnel lining during the construction of tunnels and the consequent damage procedure with TBM. They used the finite element analysis to simulate the contact deficiencies.

Kivi et al. (2012) investigated settlement control of large span underground station in Tehran metro using 3-D finite element analysis. They discussed the impact of central beam column (CBC) on the rigidity of the supporting tunnel system. Liu et al. (2012) discussed the ground movement property caused by shield tunneling and expanding construction. Ground movement and construction influence were obtained by numerical model. Wang et al. (2012) used finite element analysis to predict surface settlement above tunnel in clay till. The influence of drainage condition on surface settlement was investigated. Wang et al. (2011) applied finite element analysis to investigate the effect of tunneling induced ground movement on buried pipelines.

The numerical techniques are widely used to predict the ground movements. During the last three decades, numerical analysis has been grown rapidly (Abu Krisha, 2001; El-Nahhass, 1986; 1999; Mazek, 2005). Finite element method is considered the most appropriate analytical technique to solve geotechnical problems (Abu-Farsakh and Tumay, 1999; ElNahhas, 1999; Mazek et al., 2004). Modeling of geotechnical properties and details of tunneling procedure are the sophisticated geotechnical problem (El-Nahhass, 1986; Mazek, 2005; Mazek et al., 2004).

The surface displacement is calculated by both the FEA and the SDE developed by Peck (1969) and Schmidt (1969) based on different sand soil densities. The SDE does not consider the impact of different sand soil densities on the surface displacement. Extensive study is also conducted to discuss the impact of different tunnel diameters (D), different ground losses $\left(\mathrm{V}_{\mathrm{L}}\right)$, and different tunnel depths $(\mathrm{Z})$ on surface settlement due to tunneling. The parameters used in the SDE are discussed and established to predict surface displacement.

\section{Finite Element Model}

The finite element computer program (COSMOS/M) is used in the present study. The finite element model (FEM) takes into account the effects of the vertical overburden pressure, the lateral earth pressure, the elasto-plastic properties of the soil, and the linear properties of the metro tunnel liner. The soil, the metro tunnel liner, and the interface medium are simulated using appropriate finite elements. Fig. 1 shows the cross section along the Greater Cairo metro Line 3. The numerical modeling of the metro tunnel must reflect the characteristic of the ground continuum and the metro tunnel. In addition, the interface between the soil media and the tunnel liner should be idealized in the numerical model.

2-D plane strain elements are used for modeling the soil media and 2-D beam elements for modeling the metro tunnel liner, as shown in Fig. 2. Three-node triangular plane strain 
elements are adopted to simulate behavior of the soil media. The 2-D beam element and the triangular plane strain element interface is used between the soil media and the tunnel liner to ensure the compatibility conditions at the interface between them as well as the associated stress and strains along the interface surface.

The horizontal plane at the bottom of the mesh is represented by a rigid bedrock layer and the movement at this plane is restrained in all directions. The vertical boundaries of the 2-D FEM are restrained by roller supports to prevent a movement normal to the boundaries. The movement at the upper horizontal plane is free to simulate a free ground surface. The 2-D finite element mesh is shown in Fig. 2.

The finite element analysis is carried out to simulate the construction of Line 3 . The stress changes in surrounding soil due to tunneling are investigated to study the detailed soil behavior around the metro tunnel. The stresses in the subsoil have undergone three phases of change. At these phases, the loading steps of the metro tunnel construction are simulated using the 2-D FEA.

First phase, the initial principal stresses are computed with the absence of the metro tunnel. Second phase, the excavation of the metro tunnel is modeled by means of the FEM. The excavation is simulated by the removal of those elements inside the boundary of the metro tunnel surface to be exposed by the excavation. The excavated tunnel boundary is free to move until the soil comes into contact with the metro tunnel liner resulting from volume loss. The volume loss is considered in this study. Third phase, the calculated changes in stresses are then added to the initial principal stresses computed from the first phase to determine the final principal stresses resulting from the metro tunnel construction. Fig. 3 shows final vertical stress around the metro tunnel system. The initial in-situ vertical stresses before tunneling are calculated and plotted in Fig. 4. The final vertical stress change after tunneling is calculated and shown in Fig. 4.

\section{Boundary Condition of Tunnel System}

A parametric study is conducted to choose the suitable geometric boundaries of the 2-D numerical model. The 2-D numerical model should reflect the behavior of the metro tunnel in the field. The 2-D finite element mesh models soil block width and depth in $\mathrm{x}$ and $\mathrm{y}$ directions, respectively, as shown in Fig. 2. The calculated surface settlements of the metro tunnel against different model widths are shown in Fig. 5. When the numerical model width exceeds 100 meters there is no change in the estimated surface settlement.

The model mesh size is also studied to reflect the performance of the metro tunnel system based on the 2-D FEA. The element size is varied from $2 \mathrm{~m}, 3 \mathrm{~m}, 4 \mathrm{~m}$, up to $5 \mathrm{~m}$ along the outer boundary of the soil model block. The element size is also varied from $1 \mathrm{~m}, 1.5 \mathrm{~m}, 2 \mathrm{~m}$, $2.5 \mathrm{~m}$, up to $3 \mathrm{~m}$ along the metro tunnel liner. The calculated surface settlement based on different element sizes is presented in Table 1. The results reveal that as the element size along the outer boundary of the soil model block is smaller than three meters there is no change in calculated surface settlement due to tunneling. The results also show that as the element size along the metro tunnel liner is smaller than one meter there is no change in calculated surface settlement.

The element size is chosen to be three meters along the outer boundary of the soil block. The element size is chosen to be one meter along the boundary of the tunnel liner because of the high stress change due to tunnel excavation.

The volume loss $\left(\mathrm{V}_{\mathrm{L}}\right)$ is the ratio of the difference between excavated soil volume and tunnel volume over excavated soil volume. The $\mathrm{V}_{\mathrm{L}}$ is studied and varied from $1.5 \%$ to $4.5 \%$. Fig. 6 shows the calculated surface settlement along C.L of metro tunnel at different volume losses. 


\section{Greater Cairo Metro-Line 3 (Case Study)}

The Greater Cairo metro tunnel (Line 3) from Attaba station to Abasia station presented and discussed in the present study as a case study. Fig. 7 shows the plan of the Greater Cairo metro-Line 3. 2-D nonlinear numerical model is proposed using the FEA to understand performance of tunnel system based on a case study. The constitutive model for this analysis utilizes elasto-plastic materials. A yielding function of the Mohr-Coulomb type and a plastic potential function of the Drucker-Prager type are employed (Chen and Mizuno, 1990). The elasto-plastic parameters of different sand soil types are presented in Table 2. A linear constitutive model is employed to represent the tunnel liner. The mechanical properties of metro tunnel liner are tabulated in Table 3.

The 2-D FEA is also adopted to estimate surface settlement and vertical displacement at different locations and levels around tunnel system. The finite element mesh size of the proposed finite element model is studied. Model boundaries and volume losses $\left(\mathrm{V}_{\mathrm{L}}\right)$ are also discussed to understand the performance of the metro tunnel. Based on this study, the parametric study is conducted at volume loss of 3\%. The associated stress changes in soil due to tunneling are studied. The results obtained by the 2-D FEA are compared with those obtained by the field reading to assess the accuracy of the proposed 2-D finite element model as shown in Fig. 8. There is a good agreement between the measured readings and the calculated results.

\section{Ground Response using 2-D Finite Element Analysis}

Based on the 2-D FEA, one can proceed to predict ground response due to tunneling using different sand soil densities. In this study, loose sand, medium sand, dense sand, and very dense sand are considered around tunnel to study surface settlement due to tunneling. The nonlinear parameters of different sand soil types are presented in Table 2. The numerical analysis is carried out using the drained soil modulus (Es) calculated by the Janbu equation using different soil parameters as summarized in Table 2 (Duncan et al., 1980). The different soil parameters $(\mathrm{m}, \mathrm{e})$ are selected to simulate the behavior of different soil types.

\section{Ground Response using Surface Displacement Equation}

In this study, surface settlement around the centreline of tunnel is calculated by surface displacement equation (SDE) developed by Peck and Schmidt (1969). Peck and Schmidt (1969) proposed empirical equation to calculate surface displacement profile due to tunneling, as presented in Eq. 1.

$$
\mathrm{S}=\mathrm{S}_{\max } \exp \left(\frac{-x^{2}}{2 i^{2}}\right)
$$

In which; $S$ is the surface displacement, $S_{\max }$ is the maximum surface settlement at the point above the tunnel centerline, $\mathrm{x}$ is the distance from the tunnel centerline in transverse direction, and $i$ is the horizontal distance from the tunnel axis to the point of inflexion of the settlement trough.

The surface displacement profile could be represented by Gaussian distribution curve as presented in Fig. 9. Attewell el at. (1986) proposed (i) parameter adopted in the SDE, as written in Eq. 2.

$$
\frac{i}{R}=\mathrm{a}\left(\frac{Z_{0}}{2 R}\right)^{n} \quad \mathrm{a}=0.8 \text { to } 1.0 \quad \mathrm{n}=0.8 \text { to } 1.0
$$

Where; $Z_{0}$ is the depth of the tunnel springline below ground surface and $\mathrm{R}$ is tunnel diameter. 
The study also examined the results obtained by the SDE with different (a) and (n) parameters. The (a) parameter is varied from 0.8 to $1(0.8,0.9$ and 1$)$. The (n) parameter is varied from 0.8 to $1(0.8,0.9$, and 1$)$.

The maximum surface settlement $\left(S_{\max }\right)$ used in the SDE is determined by the 2-D FEA and the field measurements. The surface displacement induced by tunneling based on different sand soil types are predicted by both the 2-D FEA and the SDE. The FEA and the SDE are also used to calculate surface settlement due to tunneling based on different tunnel diameters (D), different volume losses, and different (Z/D) ratios. The surface displacement profiles obtained by the FEA are examined with those obtained by the SDE.

\section{Tunnel Performance under Various Parameters}

The soil investigation is discussed and analyzed in this study. Five distinct soil layers are encountered. The soil parameters are presented in Table 2. The different types of cohesionless soils are also considered in this study. The different soil parameters (m, e) used in Janbu's empirical equation (Eq. 3) (Janbu, 1963) are selected to simulate the performance of different soil types (Duncan et al., 1980).

$$
E_{s}=m P_{a}\left(\frac{\sigma_{3}}{P_{a}}\right)^{e}
$$

In which; modulus number (m) and exponent number (e) are both pure numbers, $\mathrm{Pa}$ is the atmospheric pressure expressed in appropriate units, and $\sigma_{3}$ an effective confining pressure.

The tunnel is located at different types of cohesionless soils (loose sand, medium sand, dense sand, and very dense sand). The diameter of the tunnel is varied from $7.5 \mathrm{~m}, 10 \mathrm{~m}, 12.5 \mathrm{~m}$ and $15 \mathrm{~m}$. The numerical analysis is carried out using the drained soil modulus $\left(\mathrm{E}_{\mathrm{s}}\right)$ calculated by Janbu equation as the metro tunnel passes through the sand soil.

\section{Surface Displacement due to Tunneling}

The tunnels constructed in soft ground leads to ground movement (Maroueh and Shahrour, 2008). In urban environment, this movement can affect surface and subsurface structures. Prediction of ground movement caused by tunneling is a major engineering challenge. The FEA and the SDE are used to predict the soil movement by the tunnel excavation in soft ground. In this Section, the results obtained by the SDE are compared with those obtained by FEA.

\subsection{Ground Response under Loose Sand Impact}

Parametric studies are conduct at different tunnel depths from the ground surface. The soil depth underneath tunnel invert is set to be three times the tunnel diameter (Mazek, 2005). Fig. 2 shows cross section of tunnel constructed in different sand soils.

Different tunnel diameters (D), different overburden depths (Z), and different volume losses are discussed and presented to predict ground response due to tunneling. To study ground response under different sand soil types, tunnel diameter is varied from $7.5 \mathrm{~m}$ up to $15 \mathrm{~m}$. $\mathrm{Z} / \mathrm{D}$ ratio is varied from 2.5 to 4 . The volume loss $\left(\mathrm{V}_{\mathrm{L}}\right)$ is also varied from $1.5 \%$ to $4.5 \%$.

The surface displacements obtained by the SDE are calculated based on different (a) and (n) parameters. The (a) parameter is varied from $0.8,0.9$, up to 1.0. The (n) parameter is varied from $0.8,0.9$, up to 1.0. The surface settlement profile obtained by both the FEA and the $\mathrm{SDE}$ in loose sand is shown in Fig. 10 at $\mathrm{V}_{\mathrm{L}}$ of $2.5 \%, \mathrm{D}=15 \mathrm{~m}$, and $\mathrm{Z} / \mathrm{D}=3$. 


\subsection{Ground Response under Medium Sand Impact}

Surface settlement due to tunneling is also calculated for the case of medium sand soil. The different soil parameters $(\mathrm{m}, \mathrm{e})$ are selected to simulate the behavior of medium sand soil (Duncan et al., 1980).

The surface settlement profile is predicted by both the FEA and the SDE. The study also considered different tunnel diameters (D), different volume losses $\left(\mathrm{V}_{\mathrm{L}}\right)$, and different $\mathrm{Z} / \mathrm{D}$ ratios. In the parametric study, the $\mathrm{V}_{\mathrm{L}}$ is varied from $1.5 \%$ to $4.5 \%$. The tunnel diameter is varied from $7.5 \mathrm{~m}, 10 \mathrm{~m}, 12.5 \mathrm{~m}$, to $15 \mathrm{~m}$. The $\mathrm{Z} / \mathrm{D}$ ratio is also varied from $2.5,3,3.5,4,4.5$, to 5 .

The surface displacements are computed by the SDE based on different (a) and (n) parameters. The (a) parameter is varied from 0.8, 0.9 up to 1.0. The (n) parameter is varied from $0.8,0.9$ up to 1.0. The Surface settlement profile obtained by both the FEA and the SDE is shown in Fig. 11 based on $\mathrm{V}_{\mathrm{L}}$ of $2.5 \%, \mathrm{D}=15 \mathrm{~m}$, and $\mathrm{Z} / \mathrm{D}=3$.

\subsection{Ground Response under Dense Sand Impact}

The surface displacement is calculated by both the SDE and the FEA for dense sand due to tunneling. The surface displacement profile is computed by the FEA and the SDE. The soil parameters $(\mathrm{m}, \mathrm{e})$ are selected to simulate the behavior of dense sand as presented in Table 1 (Duncan et al, 1980).

The surface settlements are calculated by both the FEA and the SDE based on different tunnel diameters (D), different volume losses $\left(\mathrm{V}_{\mathrm{L}}\right)$, and different tunnel depths $(\mathrm{Z})$. The volume loss is varied from $1.5 \%$ to $4.5 \%$. The tunnel diameter is varied from $7.5 \mathrm{~m}, 10 \mathrm{~m}, 12.5 \mathrm{~m}$, to 15 $\mathrm{m}$. The (Z/D) ratio is ranged from $2.5,3,3.5$, to 4 .

The surface displacements are calculated by the SDE based on different (a) and (n) parameters. The (a) parameter is varied from 0.8, 0.9, up to 1.0. The (n) parameter is varied from $0.8,0.9$, up to 1.0. The surface settlement profile obtained by both the FEA and the SDE is shown in Fig. 12 at $\mathrm{V}_{\mathrm{L}}$ of $2.5 \%, \mathrm{D}=15 \mathrm{~m}$, and $\mathrm{Z} / \mathrm{D}=3$.

\subsection{Ground Response under Very Dense Sand Impact}

To further understand the ground response due to tunneling, the ground surface displacement is calculated by both the SDE and the FEA at the case of very dense sand. The soil parameters $(\mathrm{m}, \mathrm{e})$ are selected to simulate the behavior of very dense sand (Duncan et al, 1980).

The parametric study also considers different tunnel diameters, different volume losses, and different overburden depths. In the parametric study, the volume loss is varied from $1.5 \%$ to $4.5 \%$. The tunnel diameter is varied from $7.5 \mathrm{~m}, 10 \mathrm{~m}, 12.5 \mathrm{~m}$, to $15 \mathrm{~m}$. The Z/D ratios are ranged from $2.5,3,3.5$, to 4 .

The surface displacement is calculated by the SDE is varied based on different (a) and (n) parameters. The (a) parameter is varied from 0.8, 0.9, up to 1.0. The (n) parameter is varied from $0.8,0.9$ up to 1.0. The surface settlement profile obtained by both the FEA and the SDE is shown in Fig. 13 at $\mathrm{V}_{\mathrm{L}}$ of $2.5 \%, \mathrm{D}=15 \mathrm{~m}$, and $\mathrm{Z} / \mathrm{D}=3$.

\section{Discussions}

The surface displacement profile computed by the FEA and the SDE are studied and compared based on different sandy soil densities. The surface settlement due to tunneling is also calculated by the SDE based on different ground losses, different overburden depths $(Z)$ and different (a) and (n) parameters, as shown in Figs. 10 to 13. The (a) parameter is varied from $0.8,0.9$, up to 1.0. The (n) parameter is varied from $0.8,0.9$, up to 1.0. In this study, the volume loss is considered to be $2.5 \%$. The tunnel diameter is considered to be $15 \mathrm{~m}$. The 
$\mathrm{Z} / \mathrm{D}$ ratio is equal to 3 . The finite element analysis takes into account strength and stress parameters of different sand soil types. However, the surface displacement equation proposed by Peck (1969) and Schmidt (1969) does not consider the impact of different sand densities.

The difference between the two sets of computed settlements is noticed in different sand densities (loose, medium, dense, and very dense). The difference between the two sets of computed settlements lies on the use of the width parameter equation (i), as presented in Fig. 9 (Attewell et al, 1986). The width parameter equation is used for cohesionless soils but it neglects the impact of different sand soil densities. Therefore, the differences between surface displacement profiles obtained by the FEA and those obtained by the SDE may be due to the value of the shear strength and stress parameters for the soil media around tunnel system. Figs. 10 to 13 show the comparison between the results obtained by both the FEA and the SDE. The surface settlements due to tunneling are calculated by the SDE with different (a) and (n) parameters.

It is also observed that the FEA takes into account the effects of volume losses. However, the surface displacement equation does not consider the impact of the volume loss. The volume loss is an important parameter effect on the performance of the tunnel system. An increase of volume loss from $1.5 \%$ to $4.5 \%$ leads to increases the estimated surface settlements due to tunneling by up to $60 \%$. The smaller the volume loss due to tunneling the smaller the calculated surface settlement.

In the case of loose sand, the surface displacement profiles obtained by the FEA are examined with those obtained by the SDE. The surface displacements calculated by the SDE are very close to those calculated by the FEA as the (a) parameter is ranged from 0.92 to 0.95 at (n) parameter to be 1.0 .

In the case of medium sand, the surface displacement profiles obtained by the FEA are examined with those obtained by the SDE. The surface displacements calculated by the SDE are very close to those calculated by the FEA as the (a) parameter is ranged from 0.89 to 0.92 at (n) parameter to be 1.0 .

In the case of dense sand, the surface displacement profiles obtained by the FEA are examined with those obtained by the SDE. The surface displacements calculated by the SDE are very close to those calculated by the FEA as the (a) parameter is ranged from 0.86 to 0.89 at $(\mathrm{n})$ parameter to be 1.0 .

In the case of very dense sand, the surface displacement profiles obtained by the FEA are examined with those obtained by the SDE. The surface displacements calculated by the SDE are very close to those calculated by the FEA as the (a) parameter is ranged from 0.82 to 0.86 at (n) parameter to be 1.0 .

Therefore, the finite element analysis gives a better estimation of surface settlement as demonstrated with the comparison between the calculated and the measured surface settlements based on the case study.

Figs. 10 to 13 show that the (n) parameter used at the (i) parameter does not give a big difference in the surface settlement. However, the (n) parameter used at the (i) width parameter is considered to be constant value $(n=1.0)$. Based on $n$ to be equal 1 , the width parameter equation (i) is used to calculate the new (a) parameter at different sand soil densities based on the FEA. Therefore, this study establishes the value of new (a) parameter for different sand soil types as summarized in Table 4. 


\section{Conclusions}

- The 2-D nonlinear finite element analysis is applicable to analyze and predict detailed performance of tunnel systems.

- The results calculated by the 2-D finite element analysis have a good agreement with the field data.

- The (n) parameter used in the (i) width parameter does not give a big difference in the surface settlement calculated by the SDE.

- The (a) parameter used in the (i) width parameter has significant effect on the surface settlement calculated by SDE.

- In the case of loose sand, the surface displacements calculated by the SDE are very close to those calculated by the FEA as the (a) parameter lies from 0.92 to 0.95 at the (n) parameter to be 1.0 .

- In the case of medium sand, the surface displacements calculated by the SDE are very close to those calculated by the FEA as the (a) parameter lies from 0.89 to 0.92 at the (n) parameter to be 1.0 .

- In the case of dense sand, the surface displacements calculated by the SDE are very close to those calculated by the FEA as the (a) parameter lies from 0.86 to 0.89 at the (n) parameter to be 1.0 .

- In the case of very dense sand the surface displacements calculated by the SDE are very close to those calculated by the FEA as the (a) parameter lies from 0.82 to 0.86 at the (n) parameter to be 1.0 .

\section{Acknowledgement}

The author acknowledges the National Authority for Tunnels (NAT) and the Egyptian Tunneling Society for the technical support.

\section{References}

[1] Abu-Krisha, A. 2001. Settlement control of CWO Sewer tunnel during boring El-Azhar road tunnels in Cairo. Proc of the International world to congress Milano, pp 3-9.

[2] Abu-Farsakh, M.Y. and Tumay, M.T. Finite element analysis of ground response due to tunnel excavation in soils. Proc. of the International Journal for Numerical and Analytical Methods in Geomechanics. Engineering, Ain Shams University, pp 524 525. Vol. 23. Egypt.

[3] Attwell, P.B. Yeates, J., and Selby, A.R., "Soil Movement induced by tunneling and their effects on Pipelines and structures", Blackie and son Ltd. Published in the USA by Chapman and Hall, 1986.

[4] Bicel, J.O., and Kuesel, T.R. 1982. Tunnel Engineering Hand Book, Published by Van Nostrand Reinhold Company, New York, USA.

[5] Byrne, P.M., Cheung, H., and Yan, L. 1987. Soil parameters for deformation analysis of sand masses. Canadian Geotechnical Journal. Vol. 24, pp 366-376.

[6] Cavalaro S. H. P., Blom C. B. M., Walraven J. C., and Aguado A. 2011. Structure analysis of control deficiencies in segmented lining. Tunneling and Underground Space Technology Vol. 26, pp. 651-127. Elsevier Ltd.

[7] Chehade, F. H., and Shahrour, I. 2008. Numerical analysis of the interaction between twin-tunnels: Influence of the relative position and construction procedure. Proc. of the Tunneling and Underground Space Technology, pp. 210-214, Vol. 23.

[8] Chen, W.F., Mizuno, E. 1990. Nonlinear analysis in soil Mechanics. Elsevier Science Publishers B.V. Netherlands 
[9] Darabi A., Ahangari Kaveh A., Noorzad A., and Arab A. 2012. Subsidence estimation utilizing various approaches - A case study: Tehran No. 3 subway line. Tunneling and Underground Space Technology Vol. 31, pp. 117-127. Elsevier.

[10] Duncan, J.M., and Chang, C.Y. 1970. Nonlinear Analysis of Stress and Strain in Soils. Journal of the Soil Mechanics and Foundation Div. ASCE, Vol. 96, No. SM5. September.

[11] Duncan, J.M., Byrne, P.M., Wong, K.S., and Mabry, P. 1980. Strength, stress-strain, and bulk modulus parameters for finite element analysis of stresses and movements in soil masses. University of California, Berkeley, CA. Report no. UCB/GT/80-01.

[12] El-Nahhas, F. M. 1986. Spatial mode of ground subsidence above advancing shielded tunnels. Proc. of International Congress on Large underground Opening, Fireze, Italy, pp. 720-725, Vol. 1.

[13] El-Nahhas, F. M. 1999. Soft ground tunneling in Egypt. Geotechnical challenges and Expectations. Proc. of the Tunneling and Underground Space Technology, Vol. 14, No. 3, pp. $245-256$.

[14] Elsayed A. A. 2011. Study of Rock-Lining Interaction for Circular Tunnels Using Finite Element Analysis", Proceeding of the Jordan Journal of Civil Engineering, pp.50 - 64 Vol. 5, No. 1.

[15] Janbu, N. 1963. Soil compressibility as determined by oedometer and triaxial tests. European conference on soil mechanics of foundation engineering. Wiesbaden. Germany. Vol. 1, pp. 19-25.

[16] Kivi A. Valizadeh, Sadaghiani M. H., and Ahmadi M. M. 2012. Numerical modeling of ground settlement control large span underground metro station in Tehran metro using central beam column (CBC). Tunneling and Underground Space Technology Vol. 28, pp. 218- 228. Elsevier Ltd.

[17] Lee, C.J., Chiang, K.H., and Kuo, C. M. 2004. Ground Movement and Tunnel Stability When Tunneling in Sandy Ground", Proc of the Journal of the Chinese Institute of Engineers, pp. 1021-1032, Vol. 27, No. 7.

[18] Liu Jiangfeng, Qi Taiyue, and Wu Zhanrui. 2012. Analysis of ground movement due to metro tunnel station driven with enlarging shield tunnels under building and its parameter sensitivity analysis. Tunneling and Underground Space Technology Vol. 28, pp. 287- 296. Elsevier.

[19] Mazek, S.A, Law, K. T., and Lau. D. T. "Numerical Analysis of Crossing Tunnel Performance", Proc of the 5th ICCAE conf. 23- 25 Nov. pp. 378 - 390, 2004.

[20] Mazek, S.A. "3-D Elasto- Plastic Finite element Analysis of Crossing Tunnels", Proc of the $5^{\text {th }}$ ICCAE conf. 23- 25 Nov. pp. $364-377,2004$.

[21] Mazek, S.A. 2005. Impact of grouting on an existing tunnel performance under passed by another tunnel. Proc of the 11 ${ }^{\text {th }}$ ICSGE. 17-19 May. Cairo, Egypt. 2005.

[22] Mazek, S.A, and El-Tehawy, E.M. 2008. Impact of Tunneling Running Side-by-Side to An Existing Tunnel on Tunnel Performance using Non-linear Analysis. Proc of the 7th ICCAE. Cairo, Egypt.

[23] Mroueh, H. and Shahrour, I. 2008. A simplified 3D model for tunnel construction using tunnel boring machines. Proc. of the Tunneling and Underground Space Technology. pp. 38-45, Vol. 23.

[24] National Authority for Tunnels (NAT). 1993. Project Document.

[25] National Authority for Tunnels (NAT). 1999. Project Document.

[26] National Authority for Tunnels (NAT). 2010. Project Document.

[27] Oettl, G., Stark, R. F., and Hofstetter, G. A. "Comparison of Elastic-Plastic Soil Models for 2-D FE Analyses of Tunneling", Proc of the Computers and Geotechnics. pp. 19-38, Vol. 23, 1998. 
[28] Peck, R. B. "Deep excavations and tunneling in soft ground", Proc. Of the $7^{\text {th }}$ Inter. Conf. on Soil Mechanics and Foundation Engineering, state - of the Art Volume, Mexico City, Mexico, pp. 225-290. 1969.

[29] Schmidt, B. "Settlement and ground movements associated with tunneling in soil", Ph.D. Thesis, University of Illinois, 1969.

[30] Vermeer, P. A., and Moller, S. C. 2008. Numerical simulation of tunnel installation. Proc. of the Tunnelling and Underground Space Technology. pp. 461-475, Vol. 23.

[31] Wang Zhechao, Wong Ron C. K., Li Shucai, and Qiao Liping. 2012. Analysis of ground movement due to metro tunnel station driven with enlarging shield tunnels under building and its parameter sensitivity analysis. Tunneling and Underground Space Technology Vol. 30, pp. 85- 92. Elsevier Ltd.

[32] Wang Yu, Shi Jaingwei, and Ng Charles. 2011. Numerical modeling of tunneling effect on buried pipelines. Canadian Geotechnical Journal, pp. 1125-1137, Vol. 48.

Table 1: Estimated surface settlement considering different elements sizes

\begin{tabular}{|c|c|c|c|c|c|c|c|c|c|c|}
\hline \multirow[t]{2}{*}{$\begin{array}{l}\text { Mesh size } \\
\quad(\mathrm{m})\end{array}$} & $\begin{array}{l}\text { Element size } \\
\text { along outer } \\
\text { boundary of } \\
\text { soil block } \\
\text { mesh }\end{array}$ & \multicolumn{2}{|c|}{$5 \mathrm{~m}$} & \multicolumn{2}{|c|}{$4 \mathrm{~m}$} & \multicolumn{2}{|c|}{$3 \mathrm{~m}^{*}$} & \multicolumn{2}{|c|}{$2 \mathrm{~m}$} & \multirow{2}{*}{$\begin{array}{l}1 \mathrm{~m} \\
1 \mathrm{~m}\end{array}$} \\
\hline & $\begin{array}{l}\text { Element size } \\
\text { along tunnel } \\
\text { liner }\end{array}$ & $1 \mathrm{~m}$ & $2 \mathrm{~m}$ & $1 \mathrm{~m}$ & $2 \mathrm{~m}$ & $1 \mathrm{~m}^{*}$ & $2 \mathrm{~m}$ & $1 \mathrm{~m}$ & $2 \mathrm{~m}$ & \\
\hline \multicolumn{2}{|c|}{ Surface Settlement (mm) } & 4.4 & 4 & 4.6 & 4.15 & 4.9 & 4.2 & 4.9 & 4.28 & 4.9 \\
\hline
\end{tabular}

* Selected element size of the 2-D finite element model

Table 2: Geotechnical Soil Parameters

\begin{tabular}{l|c|c|c|c|c|c|c|c}
\hline \hline \multicolumn{1}{c|}{ Layer } & Fill & $\begin{array}{c}\text { Upper } \\
\text { Sand }\end{array}$ & $\begin{array}{c}\text { Middle } \\
\text { Sand }\end{array}$ & $\begin{array}{c}\text { Silty- } \\
\text { Clay }\end{array}$ & $\begin{array}{c}\text { Loose } \\
\text { Sand }\end{array}$ & $\begin{array}{c}\text { Medium } \\
\text { Sand }\end{array}$ & $\begin{array}{c}\text { Dense } \\
\text { sand } \\
\text { lower } \\
\text { layer })\end{array}$ & $\begin{array}{c}\text { Very } \\
\text { dense } \\
\text { sand }\end{array}$ \\
\hline \hline Bulk Density $\gamma_{\mathrm{b}}\left(\mathrm{t} / \mathrm{m}^{3}\right)$ & 1.7 & 1.9 & 1.95 & 1.8 & 1.8 & 1.85 & 1.9 & 2.0 \\
\hline Drained Poisson's Ratio $\nu_{\mathrm{s}}$ & 0.3 & 0.3 & 0.3 & 0.35 & 0.35 & 0.30 & 0.3 & 0.25 \\
\hline $\begin{array}{l}\text { Effective Angle of Initial Friction } \\
(\phi)^{\circ}\end{array}$ & 27 & 36 & 38 & 29 & 27 & 32 & 38 & 43 \\
\hline Effective Cohesion $\mathrm{C}\left(\mathrm{KP}_{\mathrm{a}}\right)$ & 0 & 0 & 0 & 0 & 0 & 0 & 0 & 0 \\
\hline Modulus Number $(\mathrm{m})$ & 300 & 400 & 500 & 325 & 300 & 500 & 800 & 1000 \\
\hline Exponent Number $(\mathrm{n})$ & 0.74 & 0.55 & 0.52 & 0.6 & 0.6 & 0.51 & 0.5 & 0.4 \\
\hline $\begin{array}{l}\text { Coefficient of Lateral Earth } \\
\text { Pressure } \mathrm{K}_{0}\end{array}$ & 1 & 0.412 & 0.385 & 0.8 & 0.56 & 0.47 & 0.38 & 0.32 \\
\hline \hline
\end{tabular}

Table 3: Mechanical properties of metro tunnel liner

\begin{tabular}{c|c|c|c|c|c}
\hline \hline Type & $\mathrm{E}_{\mathrm{b}}\left(\mathrm{t} / \mathrm{m}^{2}\right)$ & $(\mathrm{t}) \mathrm{cm}$ & $\mathrm{F}_{\mathrm{c}}\left(\mathrm{t} / \mathrm{m}^{2}\right)$ & $\gamma\left(\mathrm{t} / \mathrm{m}^{3}\right)$ & $\mathrm{N}$ \\
\hline Tunnel liner & $2.1 \times 10^{6}$ & 50 & 4000 & 2.5 & 0.20 \\
\hline \hline
\end{tabular}


Table 4: New (a) parameter used at the (i) parameter equation at different sand soil densities

\begin{tabular}{clcc}
\hline \hline S/N & \multicolumn{1}{c}{ Sand soil type } & n-parameter & a-parameter \\
\hline \hline 1 & loose sand & 1 & $0.92-0.94$ \\
2 & medium sand & 1 & $0.9-0.92$ \\
3 & dense sand & 1 & $0.88-0.9$ \\
4 & very dense sand & 1 & $0.86-0.88$ \\
\hline \hline
\end{tabular}

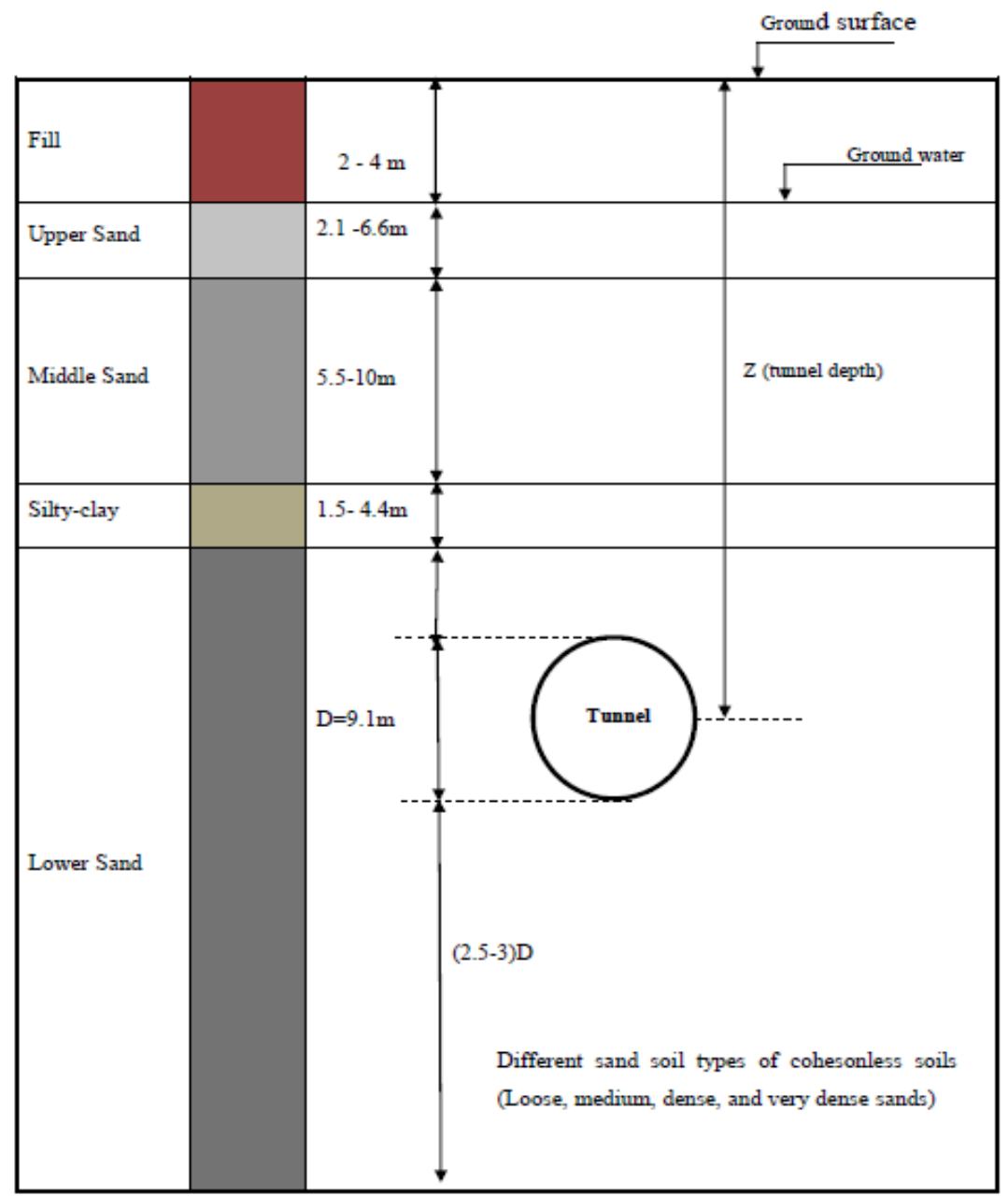

Fig. 1: Cross section shows soil parameters along the Greater Cairo metro-Line 3 (after NAT, 2010)

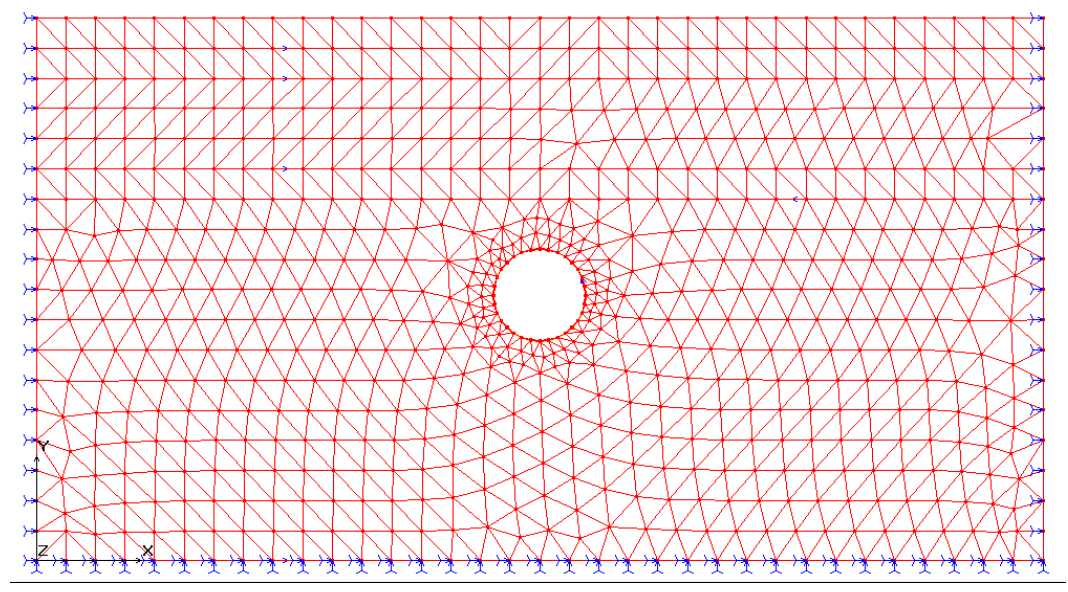

Fig. 2: 2-D finite element model of the Greater Cairo Metro-Line 3 


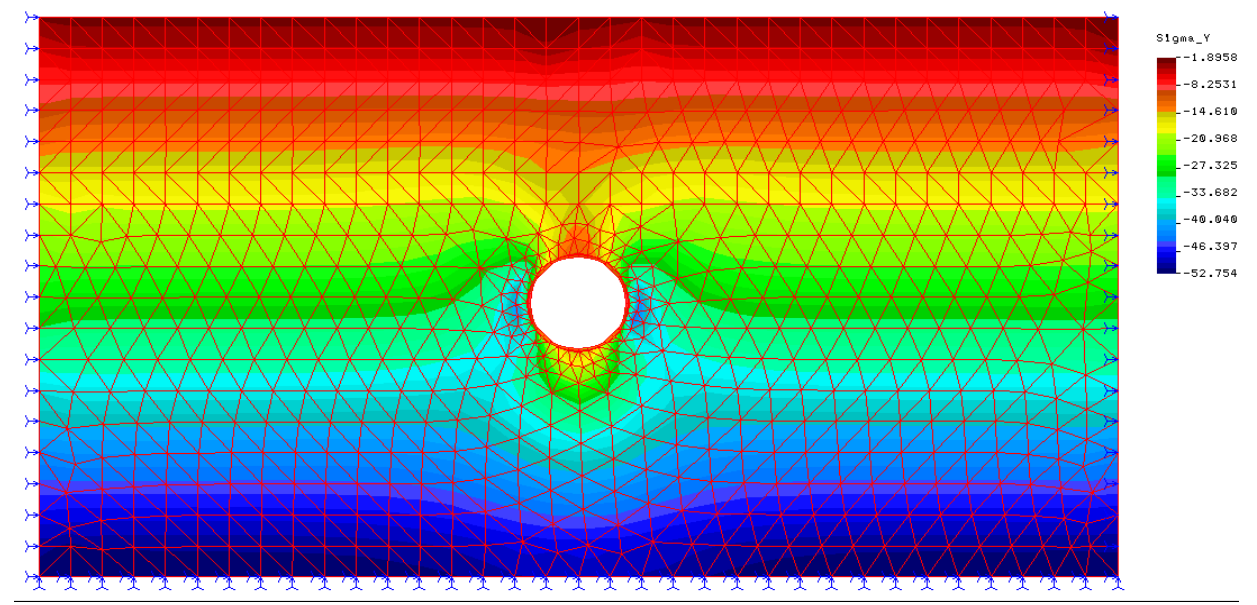

Fig. 3: Calculated final vertical stress around the metro tunnel system

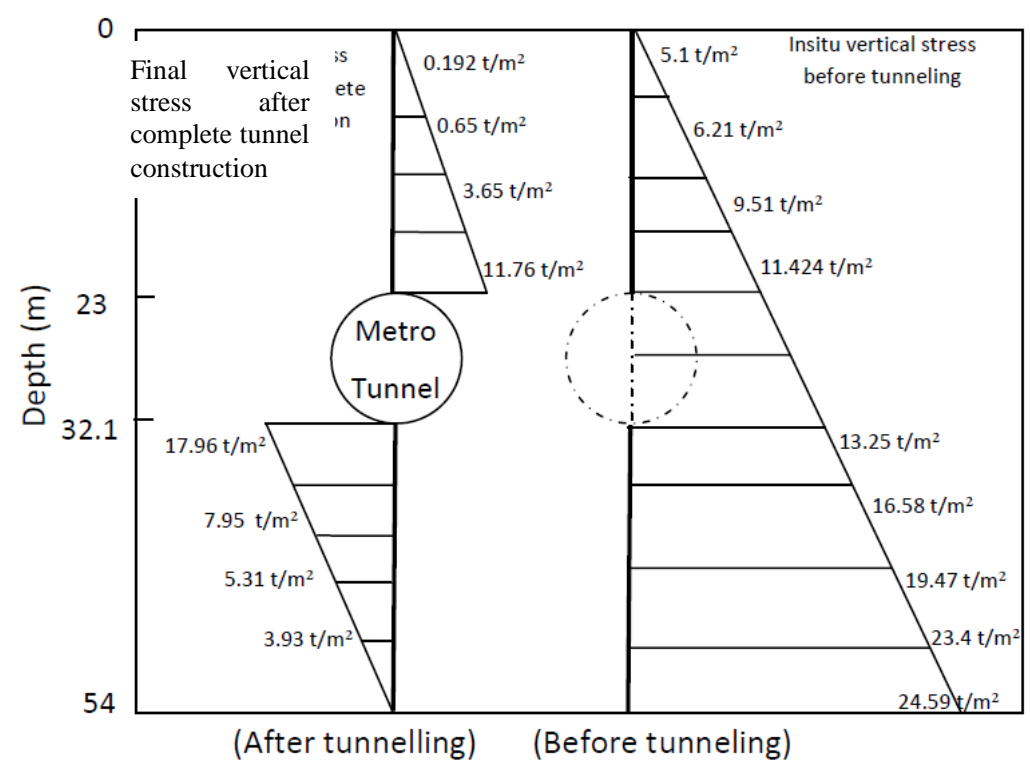

Fig. 4: Vertical stress before and after tunnelling (The Greater Cairo Metro tunnel-Line 3)

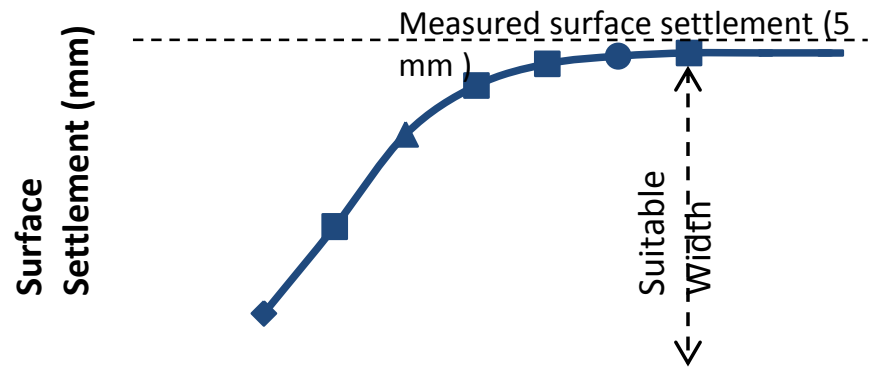

Model Width

Fig. 5: Calculated surface settlement against different model widths due to tunneling 


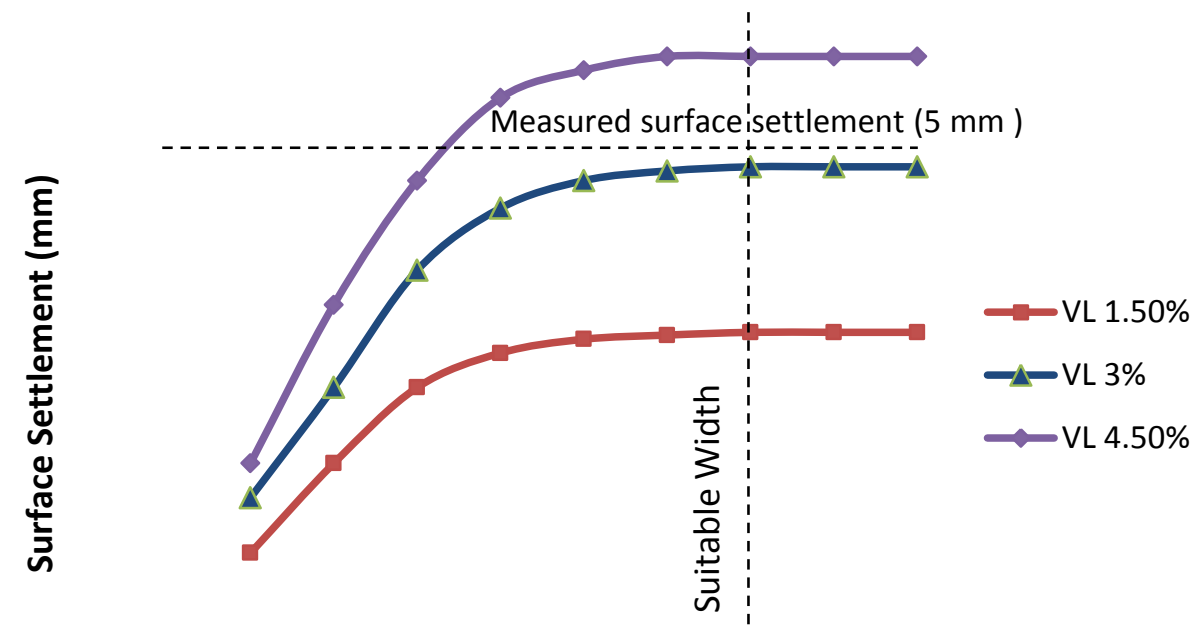

Model Width (m)

Fig. 6: Calculated surface settlement along C.L of metro tunnel at different volume losses

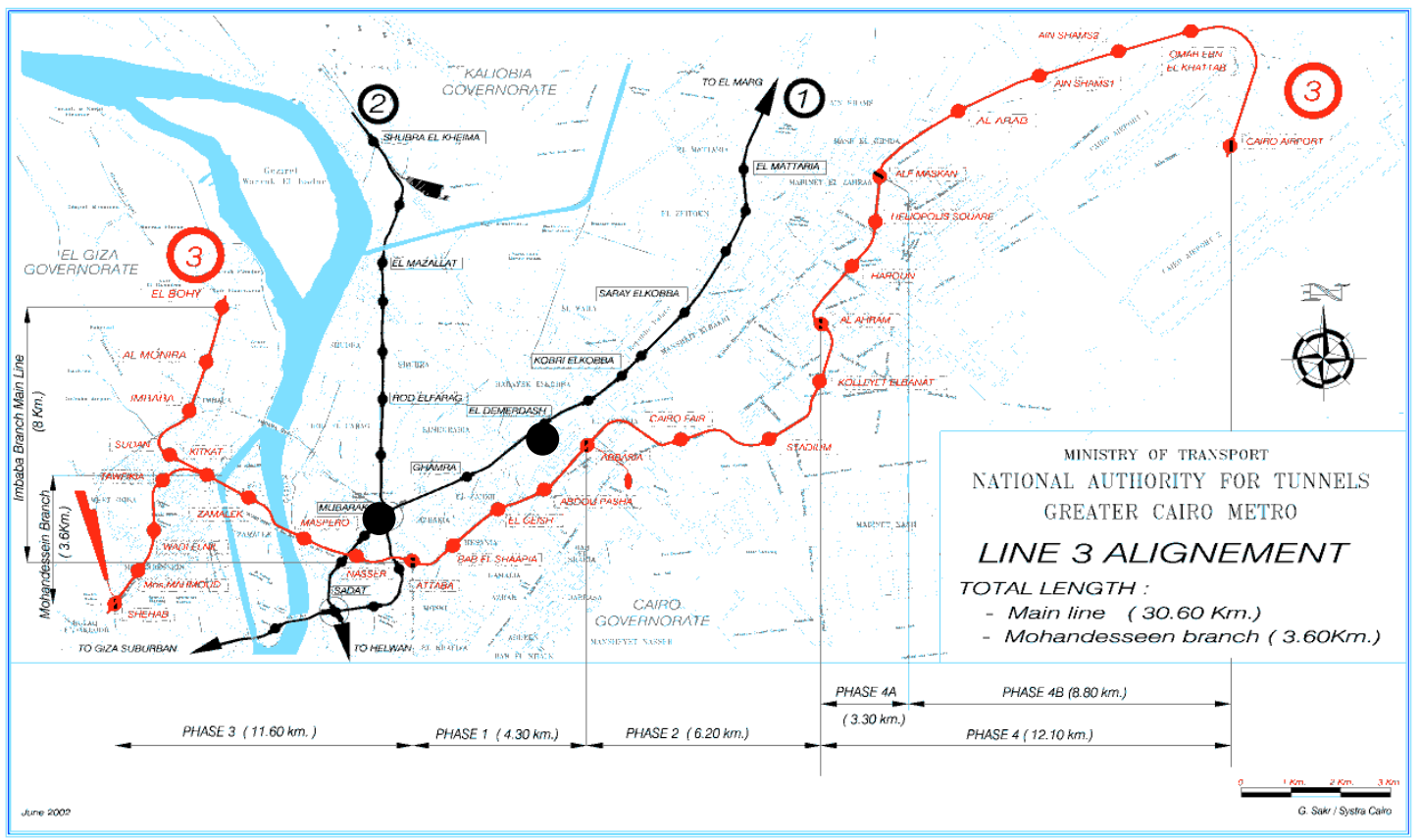

Fig. 7: Plan of the Greater Cairo metro (Line 3) 
Distance from C.L of

tunnel (m)

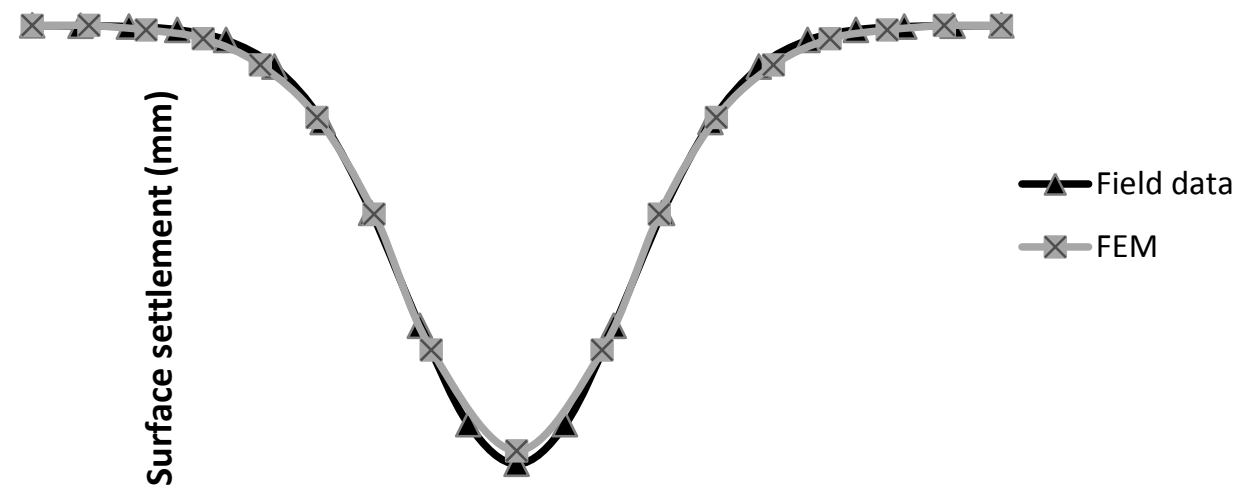

Fig. 8: Comparison between measured and calculated surface settlements along the centreline of the Grater Cairo metro tunnel-Line 3
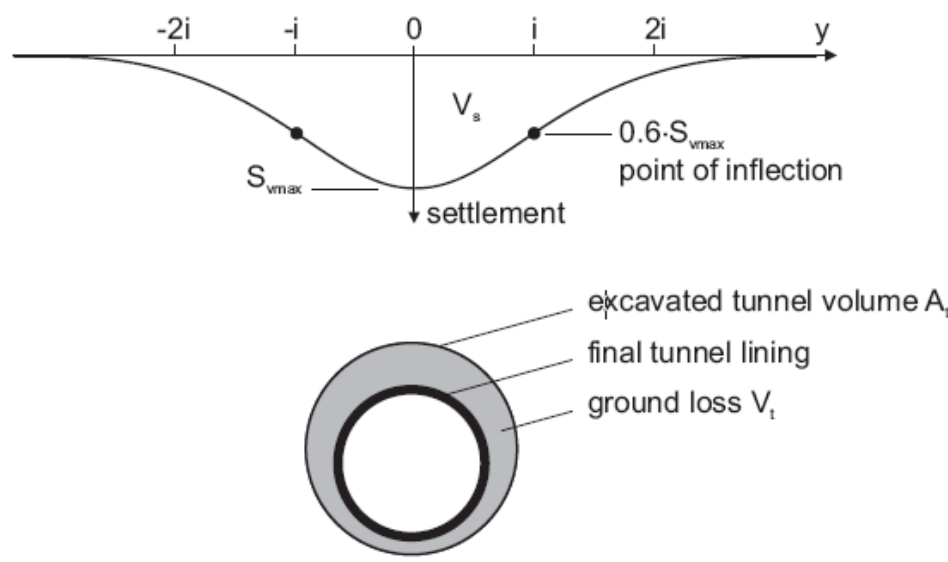

Fig. 9: Gaussian curve for transverse settlement trough (after Peck, 1969 and Schmidt, 1969) 

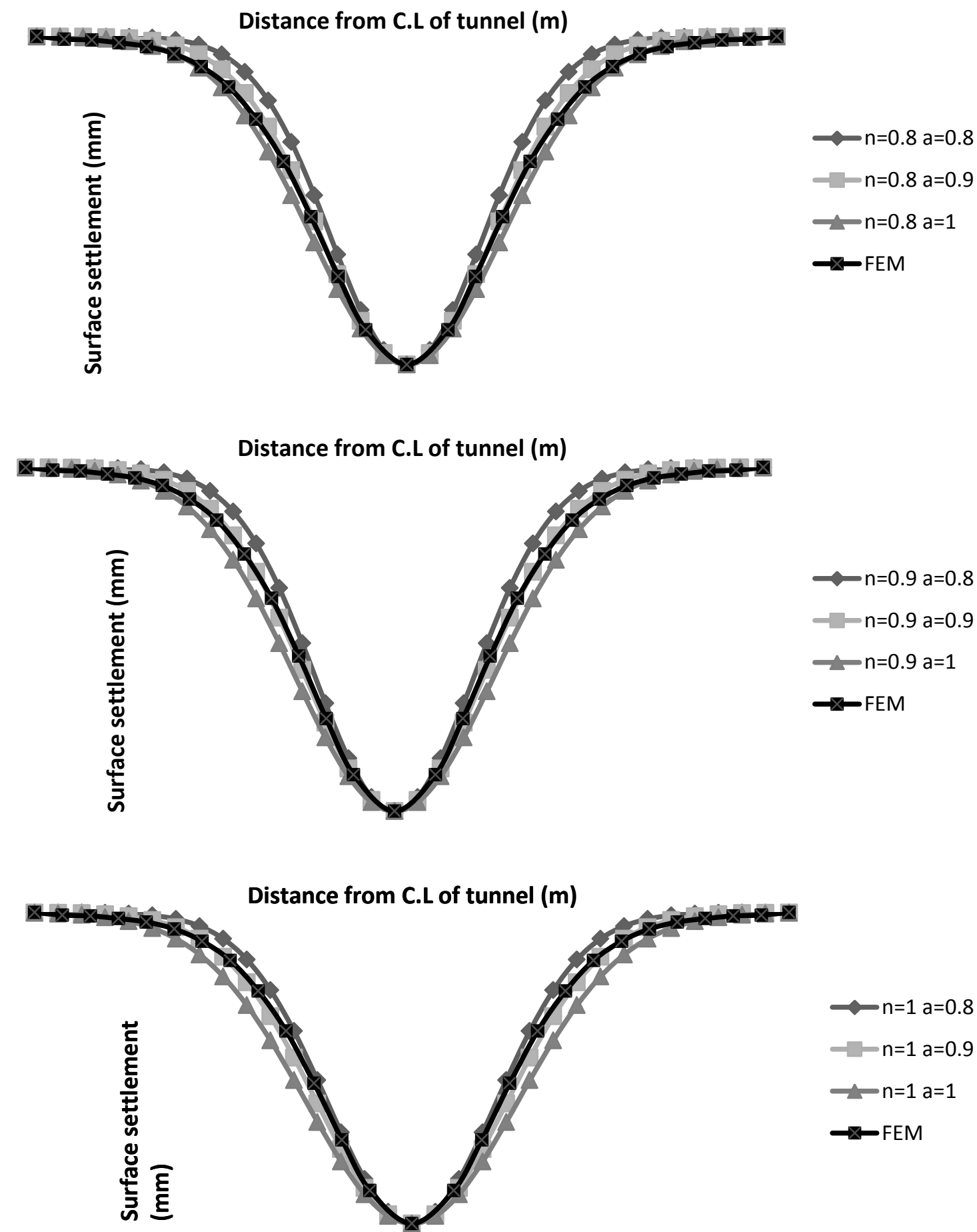

Fig. 10: Surface settlement profile obtained by both finite element analysis and surface displacement equation in loose sand (ground loss of $2.5 \%, \mathrm{D}=15 \mathrm{~m}, \mathrm{Z} / \mathrm{D}=3$ ) 

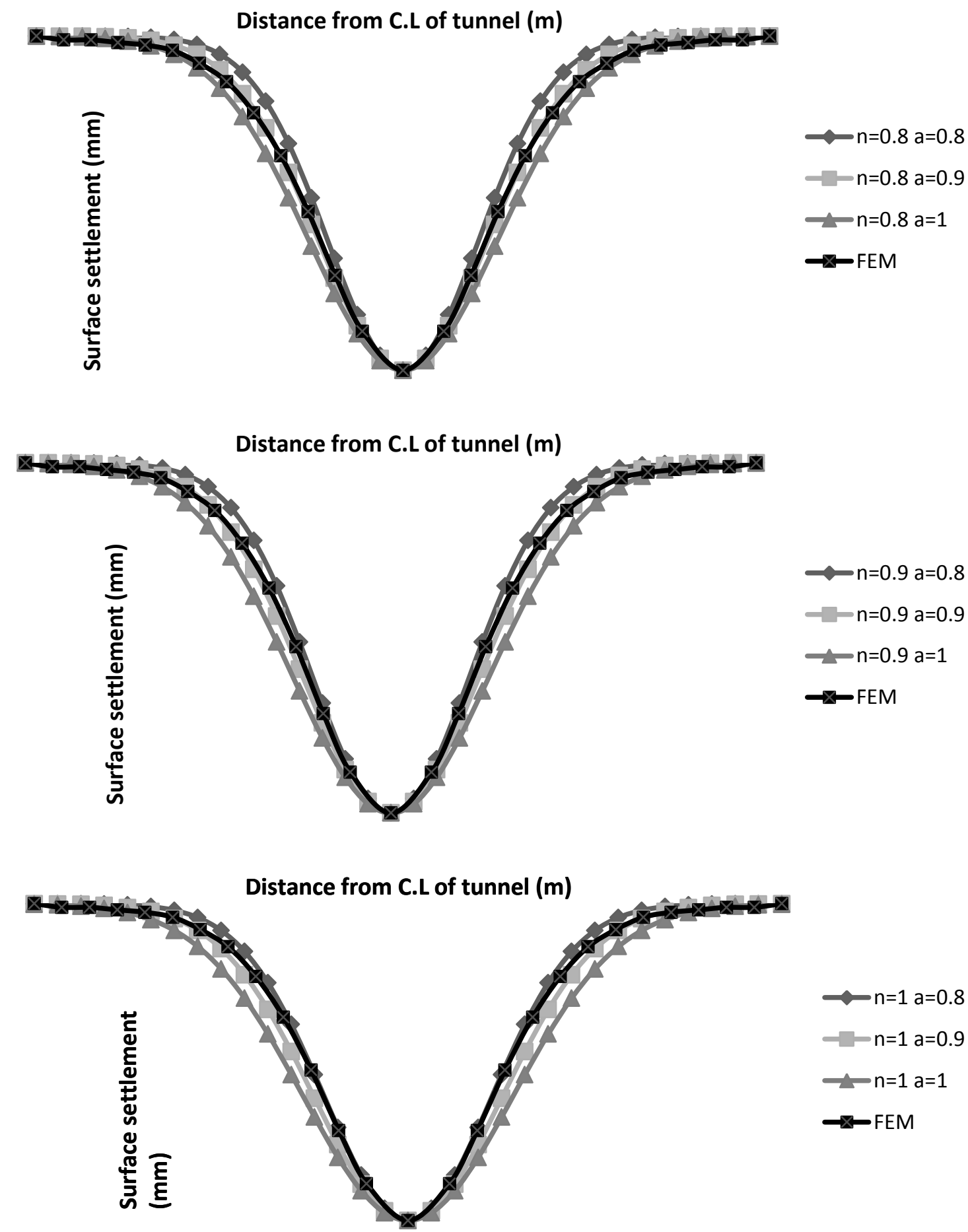

Fig. 11: Surface settlement profile obtained by both finite element analysis and surface displacement equation in medium sand (ground loss of $2.5 \%, \mathrm{D}=15 \mathrm{~m}, \mathrm{Z} / \mathrm{D}=3$ ) 

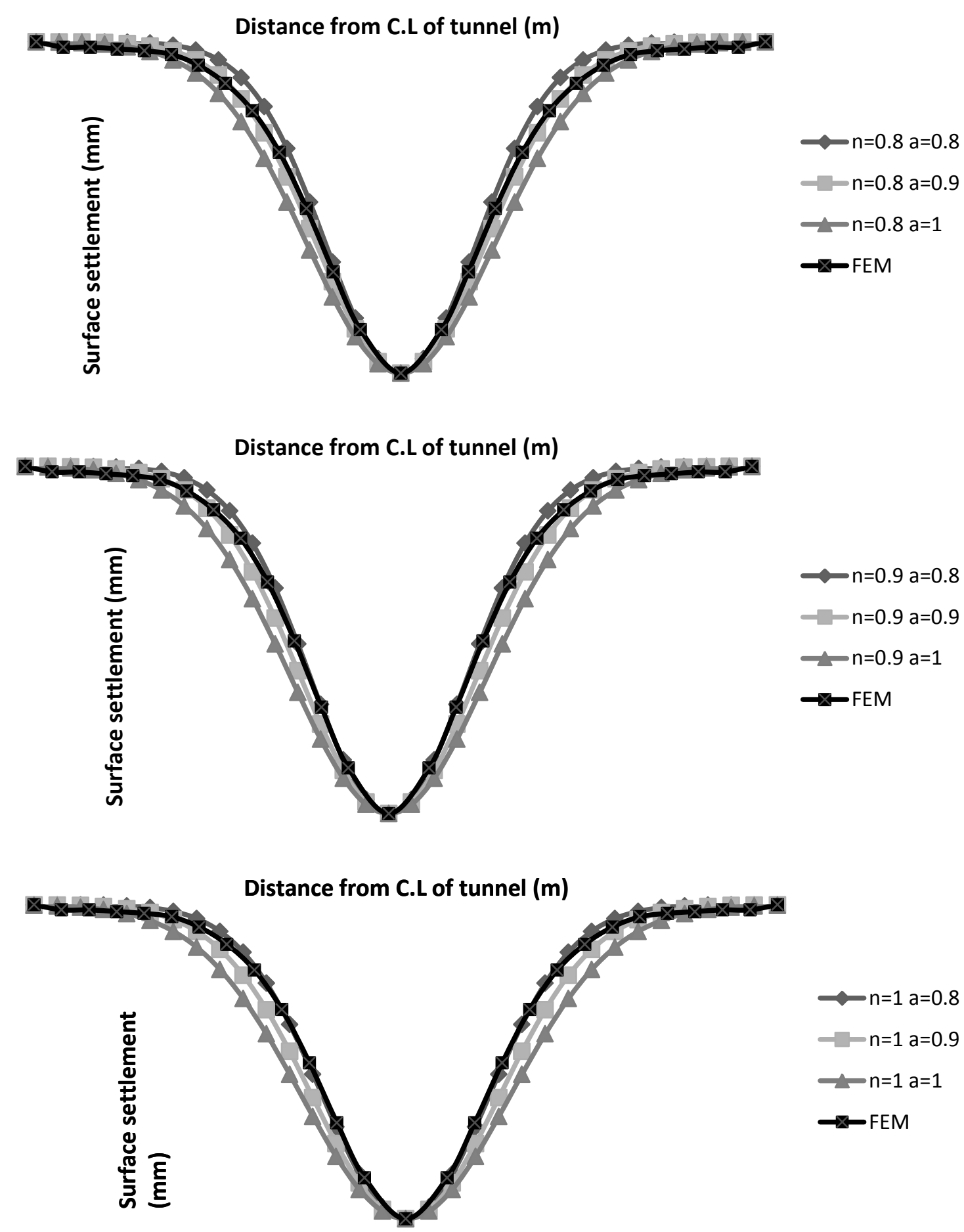

Fig. 12: Surface settlement profile obtained by both finite element analysis and surface displacement equation in dense sand

(ground loss of $2.5 \%, \mathrm{D}=15 \mathrm{~m}, \mathrm{Z} / \mathrm{D}=3$ ) 

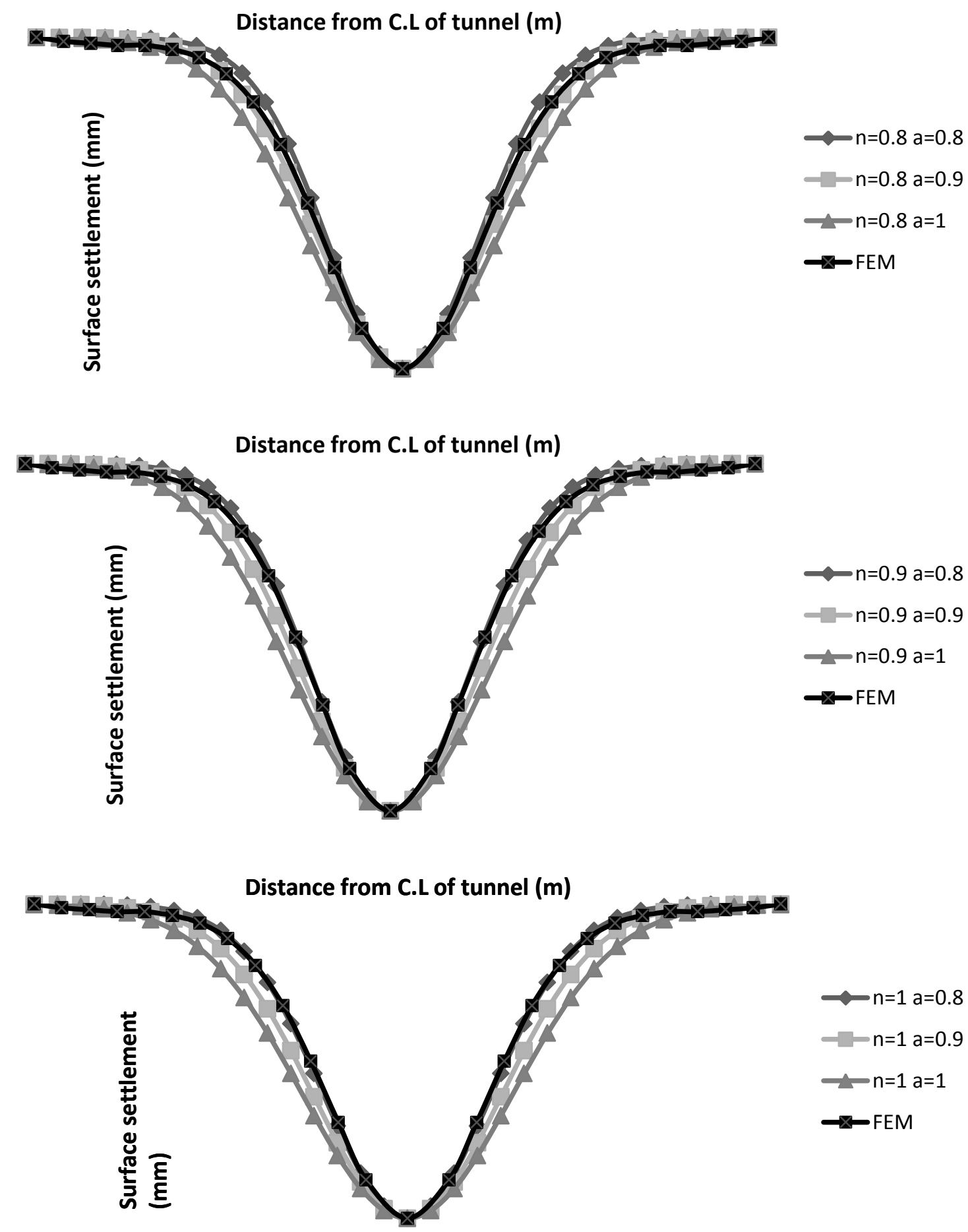

Fig. 13: Surface settlement profile obtained by both finite element analysis and surface displacement equation in very dense sand (ground loss of $2.5 \%, \mathrm{D}=15 \mathrm{~m}, \mathrm{Z} / \mathrm{D}=3$ ) 